\title{
ETNIZACIÓN Y AUTENTICIDAD DEL ESPACIO PÚBLICO Reflexiones sobre la vocación urbana del Barrio Chino porteño
}

\author{
Ethnization and authenticity of Public Space \\ Considerations on the urban vocation of Buenos Aires' Chinatown
}

\author{
Ciocoletto, Guadalupe; \\ (Facultad de Arquitectura, Diseño y Urbanismo - Universidad de Buenos Aires) \\ ciocoletto.g@gmail.com
}

\begin{abstract}
RESUMEN
La ciudad de Buenos Aires, bajo los efectos de la globalización, se ha transformado en un punto atractivo para los negocios, y el turismo se ha convertido en un importante recurso económico. A ello se le suma la inmigración como un fenómeno nuevamente en alza, y al cual entendemos como un importante modelador urbano. Esta realidad nos lleva a preguntarnos: ¿qué imágenes se generan del otro en la ciudad? ¿qué usos propone la cuidad de su imagen globalizada? Analizaremos algunas decisiones sobre el llamado Barrio Chino porteño, renovado varias veces en los últimos años: estas modificaciones habrían dado lugar a políticas de identidad y alteridad donde los símbolos identitarios-culturales son resaltados no solo por los propios habitantes sino por los espacios de poder, creando un área urbana altamente etnizada donde la diferencia cultural es resaltada para convertirse en atractivo.
\end{abstract}

Palabras clave: Espacio público, Buenos Aires, interculturalidad, etnización.

Bloque temático: espacio público y proyecto urbano en la metrópolis contemporánea.

\section{ABSTRACT}

The city of Buenos Aires, under the effects of globalization, has become an attractive point for business, and tourism turned into an important economic resource. To this, immigration is added as a phenomenon again on the rise, and which we understand as an important urban modeler. This reality leads us to ask ourselves: what images are generated about the other in the city? What uses does the city propose for its globalized image? We will analyze some decisions about the so-called Barrio Chino de Buenos Aires, renewed several times in recent years: these modifications might have led to policies of identity and alterity where the identity-cultural symbols are highlighted not only by the inhabitants themselves but by the spaces of power, creating a highly ethnized urban area where cultural difference is emphasized to become an attraction.

Keywords: Public space, Buenos Aires, interculturality, ethnization

Topic: public space and urban project in the contemporary metropolis. 


\section{Globalización, inmigración y ciudad}

No sería viable comprender a los entornos urbanos contemporáneos sin tener en cuenta las circunstancias económicas y sociales en las que están inmersos. Tampoco sería posible aceptarlos como elementos estancos e inmutables. En este sentido, para Borja y Muxi (2000) la ciudad actual es aquella que debemos repensar, inscripta en el contexto de la globalización. Como Muxí (2006:1) señala, hoy "la ciudad es considerada una inversión financiera, olvidando las coordenadas sociales, culturales, geográficas y ecológicas de cada "lugar"'. La ciudad de la globalización representa entonces un desafío, dados los crecientes cambios, desigualdades y movimientos que encarna.

Por otro lado, la migración -que si bien es un fenómeno histórico e imparable, es además un proceso constitutivo de la globalización actual (Sassen, 2002)- ha resultado en diferentes grados de diversidad cultural en las ciudades-destino. Los llamados immigrant gateways asumen diferentes formas y esto se refleja en sus espacios públicos: en la proliferación de celebraciones de diferentes culturas, mercados étnicos y otro tipo de expresiones que se reproducen en las calles, plazas y espacios disponibles. Las localidades que reciben gran cantidad de inmigrantes han comenzado a evidenciar marcas indelebles que ponen en evidencia los diferentes niveles de integración social: las calles pueden convertirse en límites o conectores, las plazas se pueden transformar en lugares animados o abandonados. La ciudad se transforma tanto en su identidad como en su significado, su estructura y el imaginario que recrea en sus habitantes. Así pues, la inmigración es un importante modelador urbano: cada ciudad ha tenido -y tendrá- que acomodarse en un camino que comprenda este fenómeno.

En las distintas ciudades-destino la inmigración ha progresivamente dado lugar a situaciones de encuentro, multiplicidad de idiomas, costumbres y tradiciones. Existe bibliografía sobre cómo la diferencia -ya sea de edad, género, clase, discapacidad, etnia, preferencia sexual, cultura, religión- interesa al urbanismo en tanto cada grupo tiene diferentes demandas en la ciudad para llevar una vida plena, en particular en el entorno construido (Sandercock, 2000, 2003). El reconocimiento del derecho a la diferencia representa un desafío para la práctica de planificación ya que las normas y los valores de la cultura dominante no sólo están integrados en su marco legislativo, sino que también están incorporados en las actitudes, los comportamientos y las prácticas de los planificadores locales. Concierne además a la planificación en tanto requiere por un lado un acercamiento desde el punto de vista político, ya que demanda recursos que están en manos de los espacios de poder: tiempo, presupuesto, mecanismos de acuerdo. Y por el otro, un acercamiento inevitablemente físico: la creación espacios democráticos, representativos y de calidad. Una planificación más democrática y culturalmente inclusiva no sólo se basa en formas diferentes de conocer y actuar, sino que también tiene que desarrollar una sensibilidad capaz de discernir cuáles métodos son más útiles y en qué circunstancias.

\section{El caso de Buenos Aires}

La inmigración extranjera en Argentina tuvo un papel preponderante en el proceso de urbanización. Buenos Aires, por su parte, es la gran "ciudad de entrada" a la Argentina donde la inmigración se ha demostrado como un fenómeno continuo y amplio: desde 1850 la cantidad de población extranjera rondó el 50\% del total de los habitantes de la Ciudad. Luego, desde la I Guerra Mundial el número comenzó a disminuir hasta llegar en el Censo de 1991 al valor relativo más bajo $(10,7 \%)$ y posteriormente aumentó, registrando el último Censo en 2010 un 13,2\% de extranjeros (Dirección General de Estadísticas y Censos - Ministerio de Hacienda, 2011). Estas variaciones ponen en evidencia el dinamismo aún vigente de la inmigración (Fig. 01). Hoy son numerosos los argentinos descendientes de distintas culturas que conviven en el territorio. 


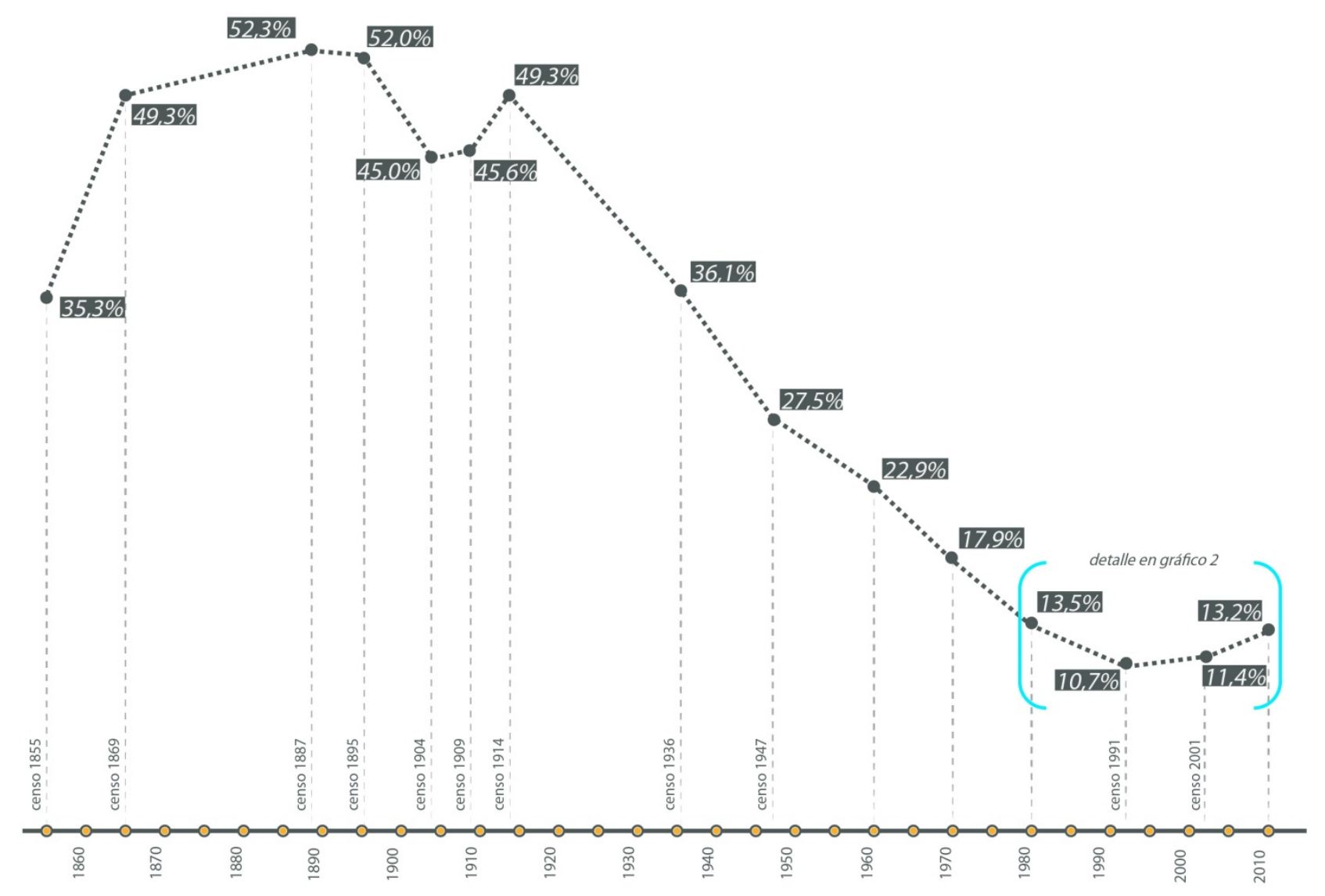

Fig. 01: Variación del porcentaje de población extranjera en la Ciudad de Buenos Aires según datos censales - Elaboración propia en base a datos de Dirección General de Estadísticas y Censos - Ministerio de Hacienda (2011)

No podemos dejar de pensar a Buenos Aires, además, como una ciudad que ha sufrido -y sufre- las huellas de la globalización (Muxí, 2009; Soja, 2008) que exceden a la inmigración extranjera que llega a su territorio: las estrategias de mercado han cobrado gran importancia y se han generado áreas de privilegio en detrimento de otras con grandes necesidades, enmascarando diferencias sociales detrás de mejoras que atienden a intereses económicos privados.

En ese contexto, existen áreas de la ciudad consideradas por el imaginario colectivo como típicos de una corriente inmigratoria en particular: el espacio típico de la inmigración italiana es el Barrio de La Boca, el de la española, la Avenida de Mayo, el de la coreana el Bajo Flores, el de las colectividades orientales, el Barrio Chino de Belgrano. A lo largo de los años algunos de éstos se han convertido en puntos de atracción y promoción turísticos (González Viaña, 2013) pero claramente no son éstos los únicos colectivos que habitan la ciudad, ni los más numerosos en la actualidad. Es por esta razón que el presente escrito intentará plantear una reflexión sobre lo que estos lugares pueden transmitir sobre la inmigración en la Ciudad y tratará de poner en discusión la autenticidad o representatividad de algunas decisiones del diseño urbano.

Con esos cuestionamientos en mente, se ha seleccionado como caso de estudio uno de los barrios étnicos porteños: el Barrio Chino de Belgrano. Tomando la definición de Sassone y Mera (2007:3) "El barrio étnico se conforma sobre la base de las relaciones personales, familiares o sociales consolidadas por las cadenas y redes migratorias. Los migrantes se asientan en el espacio urbano e impactan en él, trascendiendo el exclusivo ámbito de los miembros de la cadena." Como se expondrá en los próximos párrafos, el caso seleccionado 
corresponde a un colectivo migratorio contemporáneo cuyo arraigo es de larga data en el territorio, pero habría excedido por sus características la definición expuesta.

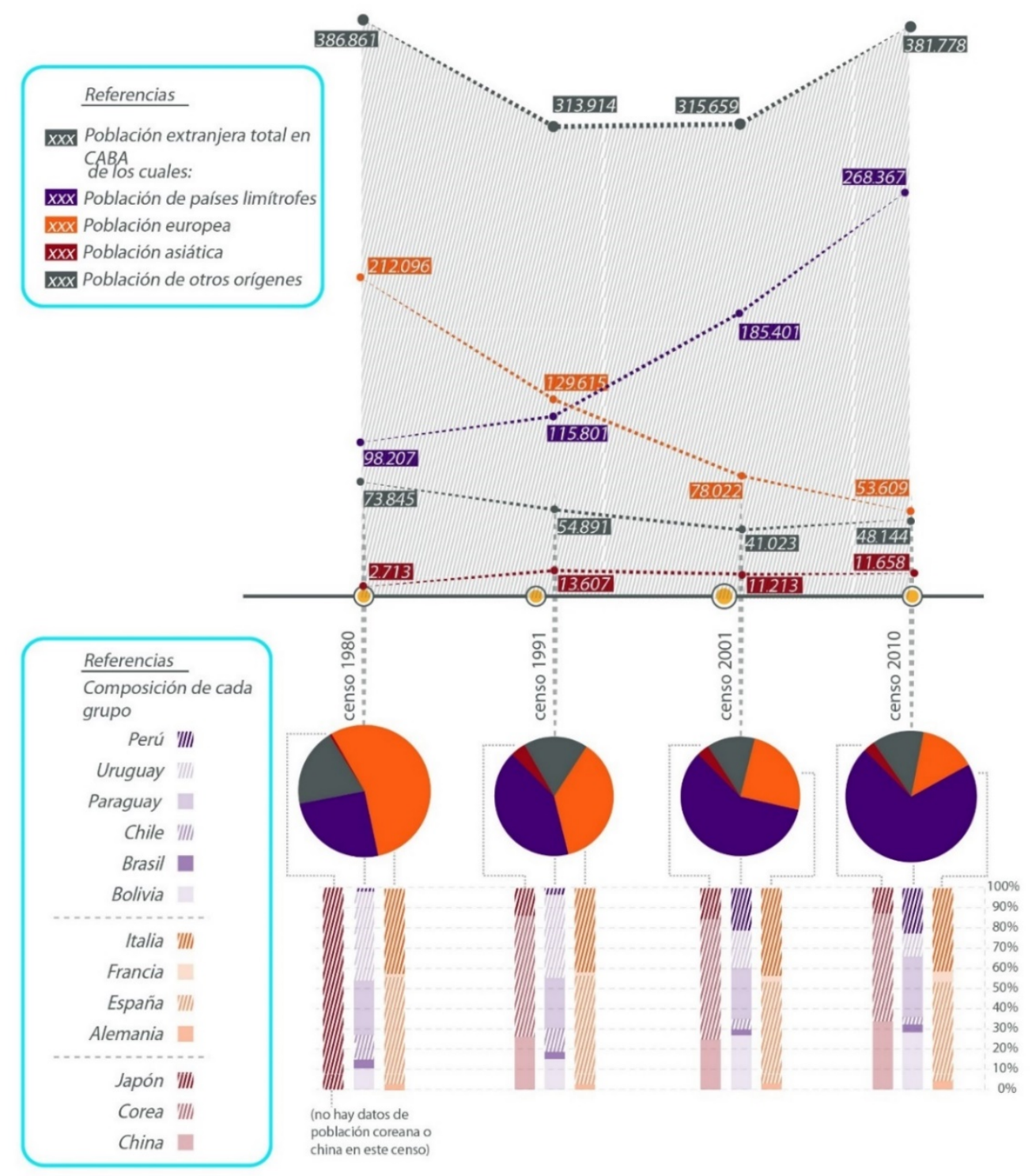

Fig. 02: Variación de la población extranjera en la Ciudad de Buenos Aires y según sus diferentes orígenes - Elaboración propia en base a datos de Dirección General de Estadísticas y Censos - Ministerio de Hacienda (2011)

Dentro del último aumento del número de inmigrantes la población extranjera que más se ha incrementado en la Ciudad es la de personas originarias de países limítrofes y del Perú (Fig. 02). Mayormente localizados en la parte Sur -donde predominan la desigualdad socioeconómica y se sitúa la mayoría de los barrios de emergencia- estos colectivos migratorios resultan a la vez en habitantes de las zonas con mayor nivel de deterioro social y urbano; y son los espacios públicos de esas áreas los que reciben la presión de los fenómenos multiculturales / multisociales, donde la diversidad de identidades se confronta. La población de origen chino representativa del caso de estudio en el presente escrito- se ubica en el doceavo puesto según los últimos datos censales. Sin embargo, según distintos trabajos (Baisotti \& Yan, 2017a, 2017b; Bogado Bordazar, 2002) fuentes extraoficiales coincidían en estimar que el número de residentes chinos en la ciudad es mucho mayor, y consideraban que en 2007 esta población conformaba, en realidad, el cuarto colectivo inmigrante. Estas 
afirmaciones fundarían la idea de que la inmigración china en el territorio es de mayor importancia a la pensada, y que aun tomando solamente las cifras oficiales se demuestra como una población de cambios dinámicos. Esta es la única comunidad que cuenta con un espacio urbano reconocido y específicamente promocionado turística y económicamente. Está, además, ubicado en la zona norte, la más próspera de la Ciudad..

Compartiendo la idea de Mera (2008) de que los discursos dominantes empoderan algunas voces y silencian otras, y reconociendo la importancia del poder simbólico de las representaciones, consideramos de importancia indagar en cuáles son esas voces definidas desde el poder y cuáles tienden a ser reprimidas desde lo urbano. La elección del Barrio Chino no ha sido hecha al azar: localizado en la zona más acomodada y rica de la ciudad y apoyado desde los espacios de poder a través de decisiones urbanísticas e impulso oficial, manifiesta una determinada postura del urbanismo y un modo de responder -o de no hacerlo- a las demandas y expresiones culturales.

\section{La comunidad china en la ciudad}

Se distinguen tres etapas de esta inmigración (Sassone \& Mera, 2007) hacia el territorio argentino: desde 1914 hasta la Revolución China de 1949, cuando fue poco significativa; la década del '80, cuando arribaron mayormente grupos familiares taiwaneses; y una última etapa, entre 1990 y 1999 cuando llega a la Ciudad un flujo importante que hace subir las cifras de chinos en Buenos Aires a la extraoficial cifra de 45000. Era de esperar que, siendo un grupo inmigrante de ultramar, la mayor cantidad de población china haya elegido la ciudad capital para residir -si bien, a lo largo del tiempo han migrado, también, hacia otras ciudades importantes del país. Desde el principio de las oleadas chinas hacia la Argentina han preferido esta ciudad para ubicarse: de las 463 personas de origen chino registradas en Argentina en 1914, vivían en la Capital Federal un 62,4 \% y en Provincia de Buenos Aires un 9,5\% (Wischñevsky, 2013). Según Wischñevsky esta preferencia se justifica al día de hoy en las posibilidades laborales, en particular con el fenómeno del supermercadismo y la posibilidad de desarrollar los pequeños comercios.

En cuanto a la composición del grupo, las diferencias internas entre chinos y taiwaneses hacen que para algunos estudiosos ( $\mathrm{Ng} \&$ Restivo, 2018; Torres, 2016) resulte difícil hablar de una comunidad china homogénea. Se manifiesta, además, como un conjunto de los más heterogéneamente distribuidos y desigualmente concentrados en el espacio y pueden identificarse en la Ciudad unidades espaciales con presencia de población china por encima del promedio en diferentes puntos, dispersos en las zonas norte, centro y sur. Esto quiere decir que no sería posible designar un Barrio Chino como tal si tomáramos solamente los aspectos residenciales de esta comunidad. Al respecto, en la Fig. 03 se manifiesta la distribución de la población china por comuna de la Ciudad según el último Censo. Se puede apreciar que, si bien algunas comunas presentan sectores de mayor concentración, la distribución en el territorio es uniforme.

\section{El Barrio Chino en la ciudad}

Así, a pesar de ser conocido como "el" Barrio Chino de la ciudad, la concentración de habitantes de ese origen en la zona no difiere de otros puntos del territorio porteño donde estos también se concentran. De hecho, la mayor proximidad espacial ante la dispersión urbana se da en el barrio de "Once" (Brauner \& Torres, 2017), más cercano al centro administrativo. El Barrio Chino tiene su nacimiento durante la última oleada de inmigración de origen Taiwanés a la ciudad. Posteriormente, se realizaron aquí los festejos del Año Nuevo Lunar y con el pasar de los años fue ganando popularidad y adquirió oficialmente el nombre de Barrio Chino en 2005 mediante una ley de la Legislatura porteña (Brauner \& Torres, 2017). Se ubica cercano a infraestructuras de transporte: terminal de autobuses, estación de trenes y grandes avenidas comerciales. Se desarrolla aproximadamente a lo largo de 300 metros sobre la calle Arribeños y algunos metros en las calles que la intersecan. Si bien mayormente contiene comercios y restaurantes -que no sólo se identifican como chinos, sino también como representativos de otros países asiáticos, por lo que sería un error asociar una única identidad al barrio- incluye funciones culturales en templos y escuelas que con el correr del tiempo, desde la 
década del ' 80 hasta hoy, han ido abriendo sus puertas e incluyendo a la comunidad local en algunas de sus actividades. Son muy populares las celebraciones por el Año Nuevo que se ofician desde 2008 en dos conmemoraciones separadas: primeramente el Año Nuevo Lunar Chino y la semana siguiente la celebración que se realiza por la Asociación de Taiwaneses (Pappier, 2011). Desde el 2010 también se celebra abierta al público la ceremonia de Vesak o Baño de Buda.
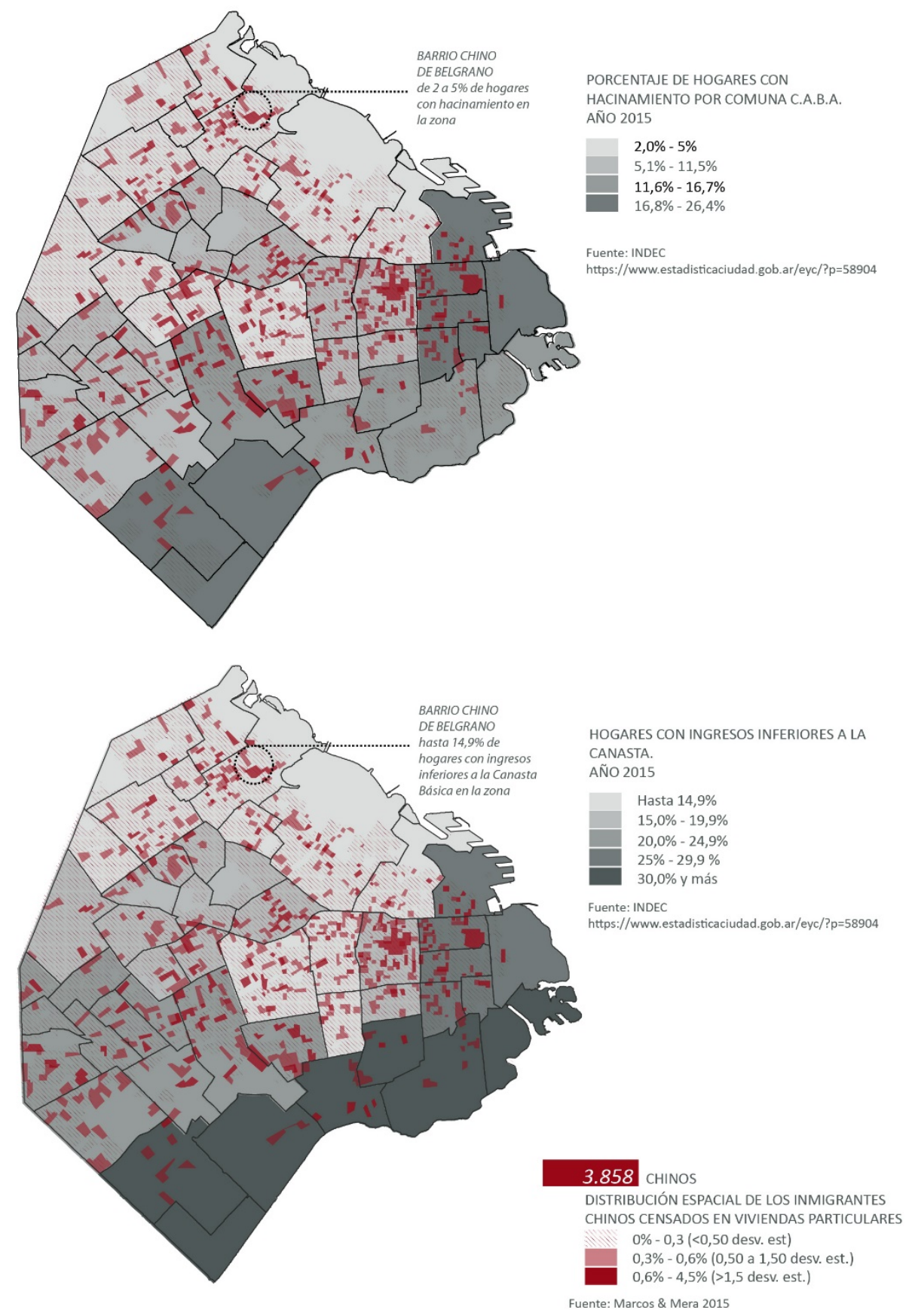

Fig 03: Concentración de las población china en la ciudad de Buenos Aires - Elaboración propia en base al estudio de Marcos y Mera (2015) 
El espacio público principal en este sector es la propia calle, -entendida como el conjunto de paso vehicular, veredas, fachadas y equipamiento. Este elemento urbano, entendido como canal de intercambio cultural, espacio de comunicación y producción de sentido, ha sido repetidamente intervenido.
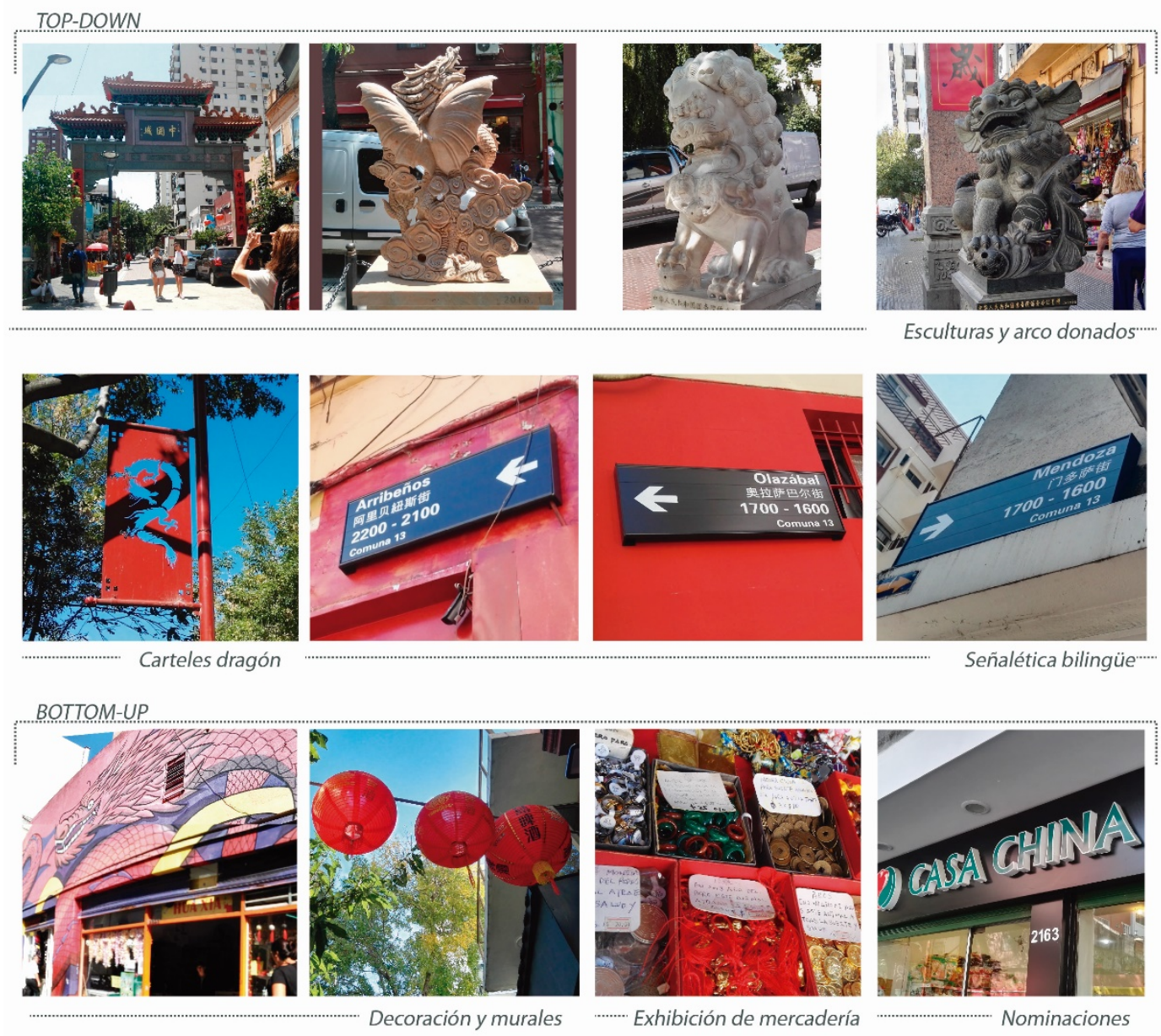

Fig 04: Estrategias de comunicación intercultural top-down y bottom-up - Relevamiento fotográfico propio.

El entorno del Barrio Chino ha sido renovado varias veces en los últimos años: en 2015 "se hicieron obras para darle prioridad al peatón y mejorar la seguridad y la circulación" (Gobierno de la Ciudad Autónoma de Buenos, 2015); en 2016 "se implementó un proyecto integral que hoy logra exaltar sus virtudes dándole mayor movilidad sustentable, ordenamiento y un mejor tratamiento de la basura." (Gobierno de la Ciudad Autónoma de Buenos, 2016b) y se inauguraron cuatro esculturas que fueron donadas por el Gobierno de China a través de su embajada -oportunidad en la cual el jefe de Gobierno Rodríguez Larreta afirmó que "Estas esculturas nos ayudan a potenciar la cultura china, es algo lindo que hacemos desde la Ciudad para seguir manteniendo esta combinación cosmopolita que hace fantástica a Buenos Aires" (Gobierno de la Ciudad Autónoma de Buenos, 2016a). Aparte de las decisiones urbanísticas de promoción y mejora del sector, todos los años se realizan celebraciones por el Año Nuevo Chino con presencia de autoridades de China y de la Ciudad de Buenos Aires, y además la visita a este sector es parte del recorrido del Bus Turístico oficial de la Ciudad.

De lo antedicho se deduce que en el mejoramiento de este sector urbano intervienen instituciones y gobiernos de ambas comunidades. El equipamiento con el que se cuenta incluye modernizadas veredas, asientos, 
arbolado, calles de circulación restringida, iluminación LED, y también nombres de calles traducidos al chino y simbología oriental: un gran arco que marca la entrada como en otros Chinatowns del mundo, esculturas y carteles. Podríamos afirmar entonces que las acciones urbanísticas que dotan de mayor caracter oriental al lugar serían principalmente decisiones top-down -'de arriba abajo', tomadas por unas pocas personas con autoridad- contra ciertas decisiones bottom-up -'de abajo arriba', desde los usuarios o comerciantes corrientes. Algunas de estas estrategias de procesamiento de información están ilustradas en las Figs. 04 y 05.
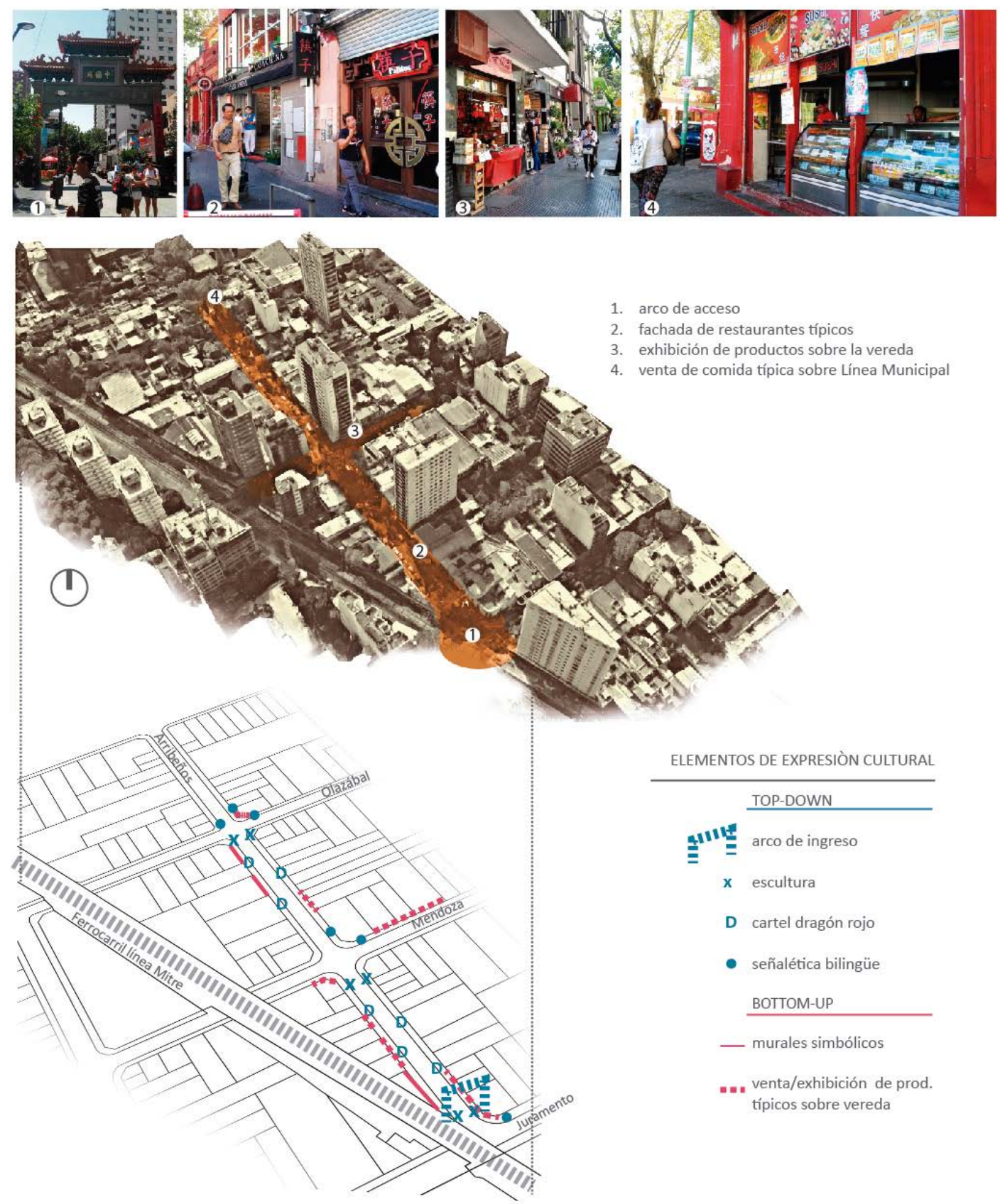

Fig 05: Situaciones urbanas y estrategias de comunicación intercultural top-down y bottom-up - Elaboración propia. 
Sintetizando: en esta porción de ciudad, la comunidad china se apropió a su llegada de un espacio vacante y lo utilizó para sus celebraciones. Posteriormente, se desarrolló en el lugar su red étnica-económica. Sobre esta estructura existente se fueron sucediendo apropiaciones y modificaciones. Pero en la actualidad encontramos algo que no ha sucedido en otros barrios étnicos de Buenos Aires, una respuesta desde el urbanismo "oficial": el equipamiento ha sido brindado, mantenido y mejorado por los gobiernos chino y argentino, la señalética es bilingüe y la invitación a visitarlo se hace desde el mismo portal web del Gobierno. Finalmente, la recualificación urbana se ha hecho convirtiendo esta zona comercial en un lugar promocionado a partir del consumo, lugar de ocio, entretenimiento y turismo, sin mencionar ni hacer mayor caso a otras problemáticas que esta población pueda tener, por ejemplo, con los propios vecinos del Barrio de Belgrano que denuncian mafias, ventas ilegales y ocupaciones del espacio que consideran fuera de la norma (Asociación Civil Vecinos de Belgrano, n.d.).

\section{Etnización, autenticidad, turismo y consumo}

Como hemos visto, en el Barrio Chino encontramos elementos que no solo hacen al confort (asientos, iluminación para peatones), sino también otros con significado socialmente compartido como representantes de lo "oriental" (carteles con dragones de color rojo, esculturas). De esta forma, y sumando la invitación al turismo que se hace desde sitios oficiales, el Barrio Chino ha ganado en solidez simbólica ante la comunidad de la Ciudad. No es la aspiración de este escrito la de establecer cuál postura se debiera tomar, pero sí la de poner bajo análisis esta situación: tenemos bajo estudio un área de alteridad simultáneamente controlada y fomentada, donde la identidad cultural viene dada verticalmente por entidades que están por sobre los usuarios del espacio. Ante la intervención de instituciones representativas se da una situación donde el resaltar la alteridad se convierte en parte de las decisiones para crear un atractivo urbano, donde los símbolos identitariosculturales son resaltados no tanto por los propios habitantes si no por los espacios de poder: "Porque ya no se trata sólo de actualizaciones y reproducciones de sentidos comunes asimétricos, sino de políticas de identidad y alteridad. Estamos en el plano del orientalismo, en el plano de las relaciones interestatales como si fueran jerárquicamente internacionales, las relaciones entre Estados y grupos étnicos, etc." (Grimson, 2000:129). Así, se habrían delimitado y resaltado las diferencias culturales entre locales y orientales en función de atraer al turismo y al consumo.

En cuanto a la autenticidad de la demarcación, podemos aportar un pensamiento de Delgado (1999:43) "Esa presunción de la ciudad como zonificada en áreas en las que vivirían acuarteladas comunidades con una identidad étnica o religiosa compartida, ha ocultado una realidad mucho más dinámica e inestable". Podríamos ampliar: la idea de identificar a una comunidad como confinada a un espacio urbano determinado ocultaría tanto las relaciones interculturales e hibrideces como las problemáticas de la propia colectividad por fuera de los límites dados -sobre todo, en un caso como este que, como se ha visto, no es el sector de mayor concentración residencial de la colectividad en cuestión.

Ante la etnización de ciertas áreas se nos presenta una reflexión sobre el control de los canales de comunicación intercultural -las esculturas, los carteles traducidos, la simbología exhibida: según Torres (2016:13) "el proceso de "etnización" coincide en algunos casos directamente con la recualificación urbana de la ciudad que enfatiza el lugar de la cultura como un recurso central para dicho proceso y contribuye a la construcción de una ciudad multicultural tanto como al control de la diferencia". Esta diferencia controlada disimularía las voces de otros tipos de diferencias -económicas, sociales- que existen con este y otros colectivos de inmigrantes, la imagen de la multiculturalidad porteña estaría siendo manipulada.

El hecho de que un espacio sea reconocido como atractivo turístico brinda un rédito económico a la ciudad, pero en este caso simultáneamente se torna en un espacio simulado e inteferido donde el encuentro con el otro ya no resulta en un descubrimiento: "Aquello que el consumidor-turista encuentra tiene que coincidir con la fotografía de la publicidad" (Muxí, 2009). Alli el contacto es más cercano a la exhibición que al diálogo. Si el proceso intercultural refiere a una expresión compartida, y ésta está intervenida desde los espacios de poder, cabe la duda sobre la autenticidad de esta comunicación. 
Reforzando lo antedicho, desde la psicología ambiental Valera (1993:79) resalta la importancia simbólica de los entornos urbanos y sostiene que la relación con el entorno "se traduce también en un verdadero "diálogo" simbólico en el cual el espacio transmite a los individuos unos determinados significados socialmente elaborados y éstos interpretan y reelaboran estos significados en un proceso de reconstrucción que enriquece ambas partes". Así, la operación desde los espacios de poder sobre los elementos de comunicación intercultural podría modificar la percepción sobre los lugares y las colectividades que los ocupan. En un marco de diversidades identitarias -especialmente en situaciones espacial y económicamente diferentes- sería entonces posible afirmar que la facilitación de elementos simbólicos, así como la de una imagen urbana positiva podría actuar en favor de unos espacios urbanos en detrimento de otros, fomentando un reconocimiento desigual por parte de terceros de cada colectividad y su espacio según intereses particulares. Es relevante también reflexionar sobre el grado de apropiación que estos modos de proporcionar -o de no proporcionarelementos simbólicos permite, si, como afirma Valera, "la apropiación del espacio puede considerarse un proceso fundamental en la configuración de la identidad social urbana" (1993:85).

Hemos analizado hasta aquí mayormente las decisiones sobre el diseño del espacio público en el Barrio Chino. Retomando la perspectiva desde las personas usuarias del lugar, podemos agregar un paralelismo con la visión de De Certau. El filósofo llama estrategia a las acciones mediante las cuales un sujeto de poder reconoce un espacio para imponerse sobre el mismo (De Certau, 1984). Esta delimitación racionaliza su accionar y le permite controlar la relación que establece con una "exterioridad" -en este caso: consumidores, turistas, comerciantes- a la vez que visualiza, vigila y predice sus variables. Coincide con esta postura Delgado (2007:14) cuando afirma que "Esa voluntad de amaestrar lo urbano es lo que explica la tarea del urbanista en muchas ocasiones, que suele ser la de propiciar la quimera política de un espacio urbano orgánico y tranquilo, estabilizado o, en cualquier caso, sometido a cambios amables y pertinentes, protegido de las dinámicas que lo convertirían a la menor oportunidad en escenario para el conflicto". Es decir, el control del espacio a través del diseño ofrece un control del usuario, limitando las posibilidades de una espontánea apropiación espacial. Se permite el uso de los elementos que han sido ya delimitados, controlando la funcionalidad de cada sector. Las dinámicas permitidas en este lugar son las del ocio y consumo, y ocasionalmente la de celebración, debidamente planificada. No se manifiestan las disputas con vecinos, ni la irregularidad de los inmigrantes no registrados, ni la discriminación hacia ellos.

Para Torres (2016:17) "El Barrio Chino de Belgrano concentra los signos y marcas culturales, pero no articula en él la vida étnica" dado que las actividades primordiales en él desarrolladas son la turística y la comercial; la comunitaria, si bien existe, es menor y no tan conocida. Si bien no se puede negar el valor del intercambio cultural que se da a través del comercio y la exhibición símbolos, cabe preguntarse qué clase de red social se desarrolla e impulsa desde la forma urbana planteada, y si ésta apoya o no las relaciones interculturales dentro de la ciudad para, simultáneamente, repensar las distintas visiones planteadas sobre los otros.

Las decisiones en pos de obtener una imagen de ciudad global guiadas por estrategias de mercado parecen haber derivado en operaciones urbanas dispares y las calidades espaciales que se han buscado y se ofrecen replican las situaciones sociales preexistentes de postergación de algunos colectivos frente a otros, menos favorecidos. Se presenta finalmente la demanda sobre la distribución desigual de recursos para generar espacios de calidad que representen a los distintos grupos que conforman el tejido social que, en algunos casos, reproduce y refuerza imaginarios sobre la inmigración resultando en barreras culturales: existen distintas clases de otros, que reciben distintas clases de atención.

Queda planteado el dilema sobre el diseño de espacios e imágenes de consumo y para ser consumidos, espacios de representación y de escenografía. Cabe preguntarse qué elementos podrían modificarse en éste y en otros barrios étnicos -algunos desprovistos de cualquier intervención- para que esa articulación en la vida étnica sea interculturalmente auténtica para quienes cotidianamente los habitan. 


\section{BIBLIOGRAFÍA}

Bogado BordazAR, L. L. (2002). Migraciones Internacionales. Influencia de la Migración China en el Río de la Plata. (Tesis de Maestría) Universidad Nacional de La Plata, La Plata.

BORJA, J. \& MuXí, Z. (2000). El espacio público, ciudad y ciudadanía. Barcelona: Electa

BRAUNER, S. \& TORRES, R. A. (2017). Identidades chinas en Buenos Aires: taiwaneses, chinos continentales y "argenchinos." Santiago, Septiembre(144), 652-665.

De Certau, M. (1984). The practice of everyday life. La Jolla, California: University of California Press.

Delgado, M. (1999). El animal público. Hacia una antropología de los espacios urbanos. (4a ed.). Barcelona: Editorial Anagrama.

- (2007). Sociedades movedizas. Pasos hacia una antropología de las calles. Barcelona: Editorial Anagrama. GRIMSON, A. (2000). Interculturalidad y comunicación. Buenos Aires: GRUPO EDITORIAL NORMA.

MerA, G. (2008). Definiendo poblaciones, construyendo diferencias. Clasificaciones estatales y categorías científicas sobre la distribución espacial de los inmigrantes. IX Congreso Argentino de Antropología Social "Fronteras de la Antropología" Posadas, Misiones, 5 al 8 de agosto de 2008. Posadas.

Muxí, Z. (2006). La ciudad dual o el reto de la globalización sobre las ciudades. Ide@ Sostenible. Espacio de Reflexión y Comunicación En Desarrollo Sostenible, Año 3 №14, 1-12

Muxí, Z. (2009). La arquitectura de la ciudad global (1a ed.). Buenos Aires: Nobuko.

PAPPIER, A. (2011). Inmigración china en Argentina: el barrio chino de Bs As como caso de estudio intercultural. Asociación Latinoamericana de Estudios de Asia y África: XIII Congreso Internacional de ALADAA - 23, 24 y 25 de marzo de 2011. Bogotá.

SoJA, E. W. (2008). Postmetrópolis. Estudios críticos sobre las ciudades y las Regiones. (Hendel V. \& Cifuentes M. Trads., Ed.). Madrid: Traficantes de Sueños.

TORRES, R. A. (2016). Los Barrios Chinos en Buenos Aires: entre diversidades, tensiones e interculturalidad. Diversidadcultural.net - Universidad de Tres de Febrero, 11(Dic 2015-Jun 2016), 1-24.

\section{Fuentes electrónicas}

Asociación CIVIL VeCINOS DE BELgRANo. (n.d.). Un antro de corrupción, habilitaciones fraguadas, procedimientos mafiosos. http://belgranodenuncia.blogspot.com/ (Consulta: 17/10/2018)

BAISOTTI, P. \& YAN, E. (2017a). Evolución y desarrollo de la inmigración china en la Argentina, https://www.researchgate.net/publication/320009003\%0AEvolución (Consulta: 30/11/2018)

- (2017b). La inmigración china en la Argentina. "Puentes" y sincretismo cultural, https://www.researchgate.net/publication/320008980\%0ALa (Consulta: 12/01/2019)

CASAS SILVA, M. R. (2016). Representaciones sociales sobre los Chinos y Taiwaneses en los medios de comunicación en Argentina. Diversidadcultural.net - Universidad de Tres de Febrero, Diciembre 2015 (11), 114. http://www.diversidadcultural.net/articulos/nro011/11-03-Mag-Romina-Silva-Casas.pdf (Consulta: 30/11/2018) 
DiRección General de Estadísticas y Censos - Ministerio de Hacienda. (2011). El aporte de la migración internacional en el crecimiento de la Ciudad de Buenos Aires. Años censales, 1855/2010. http://www.buenosaires.gob.ar/areas/hacienda/sis_estadistico/ir_2011_471.pdf (Consulta: 01/11/2015)

GobieRno de la Ciudad Autónoma de Buenos. (2015). El Barrio Chino luce renovado y con prioridad para el peatón. http://www.buenosaires.gob.ar/noticias/el-barrio-chino-luce-renovado-y-con-prioridad-para-el-peaton (Consulta: 04/01/2018)

- (2016a). Cuatro esculturas nuevas embellecen el Barrio Chino. http://www.buenosaires.gob.ar/noticias/cuatro-esculturas-nuevas-embellecen-el-barrio-chino (Consulta: 01/04/2018)

- (2016b). El renovado entorno del Barrio Chino. http://www.buenosaires.gob.ar/noticias/la-ciudad-inauguroel-nuevo-entorno-del-barrio-chino (Consulta: 04/01/2018)

- (2017). Diego Santilli participó de la celebración del Año Nuevo Chino. http://www.buenosaires.gob.ar/noticias/buenos-aires-celebra-el-ano-nuevo-chino-0 (Consulta: 04/01/2018)

GonzÁlez ViañA, M. DEL C. (2013). Cambios en la vocación del territorio. Estudio de tres enclaves porteños: Avenida de Mayo, La Boca y Barrio Chino. (Tesis Doctoral) Universidad Complutense de Madrid http://eprints.ucm.es/24611/1/T35127.pdf (Consulta: 30/11/2018)

MerA, G. \& MARcos, M. (2015). Cartografías migratorias urbanas. Distribución espacial de la población extranjera en la Ciudad de Buenos Aires (2010). Geograficando, 11(1). http://www.geograficando.fahce.unlp.edu.ar/article/view/Geov11n01a04\%0AResumen (Consulta: 30/11/2018)

NG, G., \& Restivo, N. (2018). Comunidad china: Vivir en Argentina. http://chinayamericalatina.com/comunidadchina-vivir-en-argentina/ (Consulta: 15/01/2019)

SANDERCOCK, L. (2000). When Strangers Become Neighbours: Managing Cities of Difference. Planning Theory \& Practice, 1(1), 13-30. http://doi.org/10.1080/14649350050135176 (Consulta: 24/03/2015)

- (2003). Integrating Immigrants: The Challenge for Cities, City Governments, and the City-Building Professions. Vancouver Centre of Excellence. Working Papers series No. 03-20, http://mbc.metropolis.net/assets/uploads/files/wp/2003/WP03-20.pdf (Consulta: 24/03/2015)

SASSEN, S. (2002). Global Cities and Diasporic Networks: Microsites in Global Civil Society. Global Civil Society 2002, 217-238, http://www.saskiasassen.com/PDFs/publications/Global-Cities-and-Diasporic-Networks.pdf (Consulta: 28/02/2019)

SASSONE, S. M. \& MeRA, C. (2007). Barrios de migrantes en Buenos Aires: Identidad, cultura y cohesión socioterritorial. CEISAL de latinoamericanistas -Consejo Europeo de Investigaciones Sociales de América Latina-Universidad Libre de Bruselas-Universidad Catolica de Lovaina, Preactas V Congreso Europeo CEISAL de latinoamericanistas: Las relaciones triangulares entre Europa y las Américas en el siglo XXI: expectativas y desafíos; 2007 (pp. 1-14). Bruselas. http://www.redalyc.org/pdf/740/74040601.pdf (Consulta: 06/01/2016)

ToRres, R. A. (2016). Los Barrios Chinos en Buenos Aires: entre diversidades, tensiones e interculturalidad. Diversidadcultural.net - Universidad de Tres de Febrero, 11(Dic 2015-Jun 2016), 1-24. http://www.diversidadcultural.net/articulos/nro011/11-02-Mag-Rayen-Amancay-Torres.pdf

(Consulta: 30/11/2018) 
VALERA, S. (1993). El significado social del espacio. Estudio de la identidad social y los aspectos simbólicos del espacio urbano desde la Psicología Ambiental. Universitat de Barcelona. http://www.ub.edu/escult/valera/valera.pdf (Consulta: 30/11/2018)

WISCHÑEVSKY, S. (2013). Historia de la inmigración china a la Argentina. http://dangdai.com.ar/joomla/index.php?option=com_content\&view=article\&id=2971:historia-de-lainmigracion-china-a-la-argentina\&catid=3:contribuciones\&ltemid=11 (Consulta: 15/01/2019) 